\title{
Paper
}

Cytogenet Genome Res 1974;13:11-12

\section{Summary of Human Gene Map}

F.H.

Ruddle

Chromosome

Mendelian Markers

In Vitro Markers

1

lqh + ,

Cae, Fy, AOD,

PGMi, PGD, PPH, UGPP, FH, GuK,

Amyi,

Amy 2,

Eli, Rh

Pep-C, RN5S, AK-2

2

AcPi,

MNSs

IDH-1, MDH-1, Gal-1-PT, Ifi, Hb

3

no assignment

4 or 5

$\mathrm{Hb}$, ade $+\mathrm{B}$, Es-Act

5

If a, Hex B

6

ME-1, IPO-B (SOD-2) PGM3, HLA

7 
MPI, PK-III, Hex A

8

no assignment

9

no assignment

10

GOT-1, HK

11

LDH-A, Es-A4, AcP2, AL

12

LDH-B, Pep-B, TPI, G1y+ A, CS

13

$\mathrm{RNr}$

14

$\mathrm{RNr}, \mathrm{NP}$

15

$\mathrm{RNr}$

16

$\alpha-\mathrm{Hp}$ 


\section{APRT}

17

TK

18

Pep-A

19

GPI

20

ADA

21

$\mathrm{Ag}$

RNr, IPO-A (SOD-1), AVP

22

$\mathrm{RNr}$

$\mathrm{X}$

$\mathrm{mr}, \mathrm{rp}$

, rs, oa,

. Xg, ich, cbD,

PGK, $\alpha$-Gal, HPRT, G6PD, TATr

cbP, sp, md, mdc, HemA, HemB, Xm, MPS2, cataract

no assignment

12

Ruddle Summary of Human Gene Map

Key:

$\mathrm{Cae}=$ zonular pulverulent cataract (11680)

lqh $+=$ enlarged heterochromatic segment

AOD =auriculo-osteodysplasia (10900) 


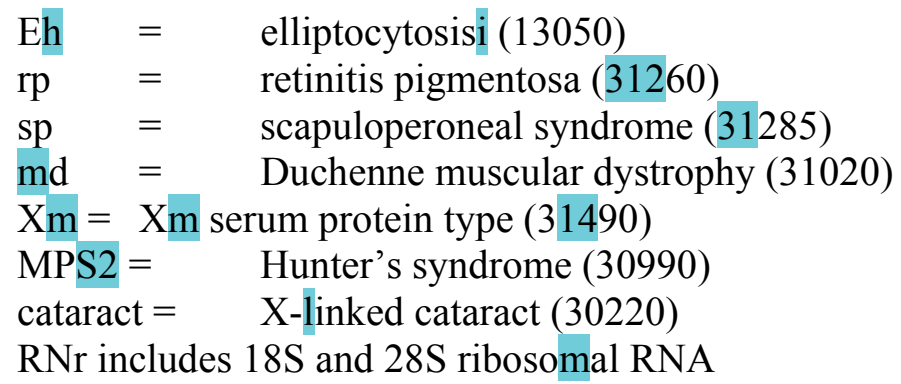

